\title{
Factors related to age at depression onset: the role of SLC6A4 methylation, sex, exposure to stressful life events and personality in a sample of inpatients suffering from major depression
}

Simon Sanwald ${ }^{1 *}$, Katharina Widenhorn-Müller', Carlos Schönfeldt-Lecuona', GenEmo Research Group, Christian Montag ${ }^{2 \dagger}$ and Markus Kiefer ${ }^{1+}$

\begin{abstract}
Background: An early onset of depression is associated with higher chronicity and disability, more stressful life events (SLES), higher negative emotionality as described by the primary emotion SADNESS and more severe depressive symptomatology compared to depression onset later in life. Additionally, methylation of the serotonin transporter gene (SLC6A4) is associated with SLEs and depressive symptoms.

Methods: We investigated the relation of SLES, SLC6A4 methylation in peripheral blood, the primary emotions SADNESS and SEEKING (measured by the Affective Neuroscience Personality Scales) as well as depressive symptom severity to age at depression onset in a sample of $N=146$ inpatients suffering from major depression.

Results: Depressed women showed higher SADNESS ( $t(91.05)=-3.17, p=0.028, d=-0.57)$ and higher SLC6A4 methylation $(t(88.79)=-2.95, p=0.02, d=-0.55)$ compared to men. There were associations between SLEs, primary emotions and depression severity, which partly differed between women and men. The Akaike information criterion (AIC) indicated the selection of a model including sex, SLES, SEEKING and SADNESS for the prediction of age at depression onset. SLC6A4 methylation was not related to depression severity, age at depression onset or SLEs in the entire group, but positively related to depression severity in women.

Conclusions: Taken together, we provide further evidence that age at depression onset is associated with SLES, personality and depression severity. However, we found no associations between age at onset and SLC6A4 methylation. The joint investigation of variables originating in biology, psychology and psychiatry could make an important contribution to understanding the development of depressive disorders by elucidating potential subtypes of depression.
\end{abstract}

Keywords: SLC6A4, DNA methylation, 5-HTTLPR, Stress, Major depression, Primary emotions, Age at onset

\footnotetext{
* Correspondence: Simon.Sanwald@uni-ulm.de

${ }^{\dagger}$ Christian Montag and Markus Kiefer contributed equally to this work.

'Department of Psychiatry and Psychotherapy III, Ulm University, Ulm, Germany

Full list of author information is available at the end of the article
}

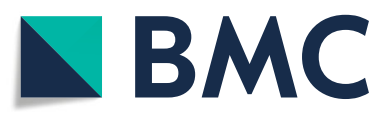

(c) The Author(s). 2021, corrected publication 2021. Open Access This article is licensed under a Creative Commons Attribution 4.0 International License, which permits use, sharing, adaptation, distribution and reproduction in any medium or format, as long as you give appropriate credit to the original author(s) and the source, provide a link to the Creative Commons licence, and indicate if changes were made. The images or other third party material in this article are included in the article's Creative Commons licence, unless indicated otherwise in a credit line to the material. If material is not included in the article's Creative Commons licence and your intended use is not permitted by statutory regulation or exceeds the permitted use, you will need to obtain permission directly from the copyright holder. To view a copy of this licence, visit http://creativecommons.org/ licenses/by/4.0/. The Creative Commons Public Domain Dedication waiver (http://creativecommons.org/publicdomain/zero/1. 0/) applies to the data made available in this article, unless otherwise stated in a credit line to the data. 


\section{Background}

Despite the high prevalence of Major Depressive Disorder (MDD) [1], there has only been limited success in identifying reliable biomarkers [2]. Reasons for difficulties in the identification and replication of depression associated genetic risk loci are now gradually becoming apparent. One complicating factor is that depression is a polygenic disorder with single genes only explaining small amounts of variance [3, 4]. Second, depression has a high lifetime prevalence of about 15\% [5]. Since depression is a common disorder showing one of the highest prevalences regarding psychiatric disorders, there is only a small mean difference in phenotypic liability between case/patient and control groups and thus reduced power to detect differences in allele frequencies between them [3]. Last, there is an ongoing debate about depression being one homogeneous clinical syndrome or a subsumption of distinct phenomenological entities under one diagnostic label [2]. Twin studies indicate that $45 \%$ of genetic liability to depression is not shared between sexes [6-8]. In addition, it has been shown that subgrouping depression according to recurrence or early age at depression onset yielded higher heritability estimations in case of recurrent depressive episodes and early onset depression $[9,10]$.

Early-onset depression may also differ from late-onset depression with respect to the course and symptoms of the disorder: Patients who had their first depressive episode early in life showed a shorter time to relapse and more residual symptoms after recovery [11]. Moreover, they reported higher chronicity and disability [12], had experienced more stressful life events (SLEs) and differed in depressive symptomatology from patients with adultonset depression [13]. High scores on the personality dimension neuroticism is considered a vulnerability factor associated with early age at depression onset [13-15]. The association of depression onset with SLEs and neuroticism is in line with a theory of depression development taking into account mammalian-brain emotional systems, bridging the gap between a dysregulation of the bodily stress system and affective changes of depression [16]. In short, this theory suggests a stressor to cause initially elevated efforts to terminate the stress response. When termination fails, a behavioral shutdown protects the individual against the fatal consequences of wasting too much resources but leaving it with lassitude and despair [17]. This theory builds upon the framework of affective neuroscience, a term coined by Panksepp [18]. Affective neuroscience theory (see also [19]) promotes the view that human personality is anchored in primary emotional systems comprising the fundamental emotional tendencies common among all mammals [20-22]. According to the above theory of depression development, depression is mainly associated with two primary emotions: SEEKING and SADNESS
[16]. The SEEKING system is utilized by other primary emotions and is defined as the effort made to mitigate a negative emotional state or the search for vital resources. SADNESS on the other hand is triggered by separation distress such as the loss of a child or being apart from a loved one (in humans the separation or loss may also be a symbolic one) and eventually precipitates depression [20]. Both, low SEEKING and high SADNESS are associated with depression severity [23] but whether they are associated with age at depression onset has, to the best of our knowledge, not yet been investigated.

At the same time the serotonin (5-HT) system has a long history in the research on the pathophysiology of affective disorders [24]. Early theories of depression development postulate depression to originate from a dysfunction of monoaminergic neurotransmission. More recent theories suggest a modulating and not a causal role of 5-HT in the etiology of depression [24]. Considering its important role for early theories of depression development, it is not surprising that the 5-HT system has often been investigated in search for genetic markers of depression risk. The serotonin transporter (5-HTT) is one of the most investigated parameters of the 5-HT system in depression research $[25,26] .5$-HTT is one of several structurally similar transporter proteins having a high affinity for monoamines. These presynaptic membrane proteins transport their substrate from the extracellular space to the cytoplasm terminating serotonergic neurotransmission and recycling presynaptic supplies of serotonin [27]. The interest in the 5-HTT originates from antidepressants such as selective serotonin reuptake inhibitors (SSRIs) directly binding to 5-HTT inhibiting 5-HT reuptake [28]. As a consequence of SSRI treatment, 5-HTT is highly regulated and undergoes adaptive changes [29]. The SLC6A4 gene encoding the 5-HTT, is located on chromosome 17 q.11.1-q12 [30], has a length of 31 kilo bases and contains 14 exons [31]. The serotonin transporter linked polymorphic region (5HTTLPR) - a repeat length polymorphism - is one of the most investigated polymorphisms in depression research [32]. The short (S) allele is associated with a lower transcription rate of the 5-HTT compared with the long (L) allele [33]. Former reports of carriers of the $\mathrm{S}$-allele being more likely to develop MDD as a function of SLEs (and sometimes sex) could not be confirmed in a recent meta-analysis [32].

However, in the last years another field of research emerged impressively demonstrating that the transcriptional apparatus and thus the phenotype is not hardwired by the genome. In fact, the genome is the individual starting point for adaptation processes becoming necessary during cellular differentiation and due to individually different environmental challenges. The name epigenetics became established as term for 
processes bridging the gap between genotype and phenotype [34]. The most investigated epigenetic mechanism is DNA-methylation [35]. DNA-methylation has mostly been examined in cytosine-phosphate-guanine (CpG) dinucleotides. In $\mathrm{CpG}$ dinucleotides a methyl group is added to the $5^{\prime}$-position of the cytosine residue [35]. CpG-methylation affects histone DNA interactions thereby modulating a gene's accessibility for transcription factors and thus transcriptional activity [36, 37]. This is not surprising in light of the fact that CpG rich regions are frequently located in the promoter regions of genes [38].

Increased methylation of the whole $\mathrm{CpG}$ island or specific CpG sites in the promoter region of the SLC6A4 gene has already been associated with decreased transcription rate [39], lower mRNA concentrations [40], SLEs and recent depressive symptoms [41, 42], family history of depression [43] as well as post-stroke depression [44]. There are, however, ambiguous results regarding the association between SLC6A4 promoter methylation and depression severity [42, 43, 45-47]. In addition, there are reports of an interaction of 5-HTTL PR genotype and DNA-methylation in the investigation of the effects of stress on stress-related phenotypes [40, 48]. Thus, variations in SLC6A4 expression need to be integrated with the contribution arising from genetic as well as epigenetic mechanisms [49]. However, DNA methylation may also be sex specific. Especially in depression with its sexually dimorphic risk for depression development [50]. Accordingly, $\mathrm{CpG}$ sites in the SLC6A4 gene have been reported to be differentially methylated as a function of sex with females exhibiting higher SLC6A4 methylation than men [51]. Therefore, sex by genotype interactions should be explored when investigating SLC6A4 methylation in depression.

Taken together, depression can be understood as reduced SEEKING/higher SADNESS as a consequence of chronically prolonged separation distress [16]. The 5-HT system plays an important role in affective disorders [52] with the 5-HTT being the target for a large group of antidepressants [28]. Furthermore, SLEs are associated with SLC6A4 methylation and early-onset depression $[13,41]$. Early-onset depression has been shown to have a higher heritability compared to the investigation of depression independent of age at onset [10]. There are findings of interactions between sex and genetic as well as epigenetic layers of SLC6A4 regulation [40, 48, 51]. Thus, we wanted to examine the relation of SLEs, primary emotions, DNA-methylation of SLC6A4 and their interactions to age at depression onset in a sample of inpatients suffering from MDD. We assumed depression onset to be positively associated with SLEs, SADNESS and depression severity and negatively associated with SEEKING. We also assumed an association between age at onset and SLC6A4 methylation. Considering the heterogeneity of findings in previous studies, we did not infer a directional hypothesis for associations between age at onset and SLC6A4 methylation. In addition, we wanted to explore possible sex differences between SLEs, primary emotions, age at depression onset, SLC6A4 methylation and depression severity. Last, we wanted to examine which factors (sex, SLEs, primary emotions, 5HTTLPR genotype and SLC6A4 methylation) or interactions of factors predict age at depression onset.

\section{Methods \\ Participants}

Data of $N=146$ inpatients $(n=95$ females, age: $M=$ $38.74, S D=14.25$ ) diagnosed for major depression at the time of admission to the hospital was taken from the database of the Ulm Gene Brain Behavior Project (UGBBP). Data from this sample was used for earlier studies focusing on other parameters [23, 53, 54]. All inpatients were recruited at the Department of Psychiatry and Psychotherapy III at Ulm University, Ulm, Germany. They were diagnosed for Major Depression by a psychiatrist at admission to the hospital using the Structured Clinical Interview for DSM-IV (SCID-I) [55]. Participants were administered the self-assessment questionnaires described below. Depression severity was rated by a trained interviewer using the Montgomery Asberg Depression Rating Scale (MADRS) [56]. Sociodemographic data was collected with a standardized semi-structured interview based on an in-house questionnaire. Further, we assessed age, Body Mass Index (BMI in $\left.\mathrm{kg} / \mathrm{m}^{2}\right)$, consumed alcohol (grams/day) and nicotine (cigarettes/day). Patients were asked when they had had their first episode of at least 2 weeks suffering from depressive mood, loss of interest and other depressive symptoms. We calculated dose equivalents for current antidepressants (weighted mean dose/fluoxetin40 mg) [57] and neuroleptics (weighted mean dose/chlorpromazine100 mg) [58-60]. Two patients fulfilled the DSM-IV criteria [55] for alcohol abuse but not alcohol dependence. We decided to include them in our analyses since we controlled for alcohol consumption. One patient had the diagnosis of a sexual dysfunction not otherwise specified. $56.8 \%$ of inpatients $(n=83)$ reported to know about the presence of psychiatric disorders in their family (depression: $n=56$ with $n=38$ in parents or siblings and $n=18$ in more distant relatives or not otherwise specified; schizophrenia: $n=5$ with $n=2$ in parents or siblings; anxiety: $n=4$ with $n=2$ in parents or siblings; personality disorders: $n=3$ with $n=1$ in siblings; bipolar disorder: $n=2$ in parents or siblings; eating disorders: $n=3$ in more distant relatives; substance abuse: $n=2$ with $n=1$ in both parents and siblings; obsessive compulsive disorder: $n=1$ in parents; attention deficit syndrome: 
$n=1$ in siblings; not otherwise specified: $n=19$ ). Median age at depression onset was 21 years. Please note that there is an overlap between the present manuscript and older publications [23], where the ANPS has been investigated in the context of BDI scores in a casecontrol design (but without SLEs and epigenetic variables).

\section{Questionnaires \\ CLEQ}

The Critical Life Events Questionnaire (CLEQ) assesses 30 traumatic life events such as sexual abuse, experience of violence or death of a close person. The participants answered a question of whether they had ever experienced the concerning event [61]. We calculated a score adding up the experienced events. If there were 9 or more unanswered events, participants were excluded from further analysis with the CLEQ.

\section{Affective neuroscience personality scales (ANPS)}

The ANPS German version [62] comprises 110 items assessing individual tendencies in six primary emotional systems: SEEKING, CARE, PLAY (positive emotionality) and FEAR, ANGER, SADNESS (negative emotionality). The primary emotion of LUST may potentially have negative carry over effects on the remaining items, if items on one's own sexual behavior would be filled in. All items are answered on a four point Likert scale ranging from strongly disagree [1] to strongly agree [4]. Internal consistency of the SEEKING scale was acceptable ( $\alpha=.77, n=110, n=36$ were excluded listwise), internal consistency of the SADNESS scale was also acceptable ( $\alpha=.73, n=116, n=30$ were excluded listwise).

\section{BDI-II}

Severity levels of depressive symptoms were explored by using the Beck Depression Inventory (German version, BDI-II) [63]. The BDI-II is an internationally recognized clinical and research psychopathological-psychometric instrument recording the severity of a depressive syndrome. The BDI-II is a self-assessment scale and comprises 21 items. For each item ratings between 0 (not at all) and 3 (very intensive) are given depending on the symptom severity. A maximum of 63 points in total can be reached. Internal consistency was good with $\alpha=.84$.

\section{Genotyping of 5-HTTLPR}

DNA extraction from whole blood samples was performed on MagNA Pure 96 using a commercial extraction kit (Roche, Mannheim, Germany). Genotyping of the 5-HTTLPR including rs25531 was carried out as described in Lachmann and colleagues [64]. The combination of information from the 5-HTTLPR and rs25531 results in the distinction between the variants $\mathrm{L}_{\mathrm{A}}$ and
$\mathrm{L}_{\mathrm{G}} \cdot \mathrm{L}_{\mathrm{G}}$ is functionally similar to the $\mathrm{S}$ allele [65]. Frequencies of 5-HTTLPR/rs25531 genotype fulfilled Hardy-Weinberg-Equilibrium expectations with respect to 5 -HTTLPR $\left(49 \mathrm{~L} / \mathrm{L}, 72 \mathrm{~L} / \mathrm{S}, 23 \mathrm{~S} / \mathrm{S} ; \chi^{2}(1)=0.16, p=\right.$ 0.69). To maximize statistical power, groups were dichotomized into $\mathrm{L}_{\mathrm{A}} \mathrm{L}_{\mathrm{A}}$ homozygotes and $\mathrm{S} / \mathrm{L}_{\mathrm{G}}$ carriers (42 $\left.\mathrm{L}_{\mathrm{A}} \mathrm{L}_{\mathrm{A}}, 102 \mathrm{~S} / \mathrm{L}_{\mathrm{G}}\right)$.

\section{Quantification of SLC6A4 promoter methylation}

Methylation status of the SLC6A4 gene (Fig. 1) was quantified by Varionostic GmbH (Ulm, Germany) using the Sequenom Epityper MassArray System (San Diego, CA, USA). All steps of the EpiTYPER assay were performed under routine conditions as described by Suchiman and colleagues [66]. Genomic DNA from peripheral blood was bisulfite treated. Amplicons for the CpG-rich region in the SLC6A4 promoter (chr17:30235345-30,236,068; amplicon 1: chr17:3023534530,235,765; amplicon 2: chr17:30235734-30,236,068; hg38) were designed using Agena's EpiDESIGNER software (San Diego, CA, USA). These amplicons were PCR amplified using the following primers: amplicon 1: forward (aggaagagagG GTTATTTAGAGATT AGATTATGTGAG GGT) and reverse (cagtaatacgactcactatagggagaaggctCA ACAATAAACAAAAAAACCCCCTA); amplicon 2: forward (aggaagagagG GGTTTTTATATGGTTTGATTTT TAG) and reverse (cagtaatacgactcactatagggagaaggctCACCTACTCCTTTATACAACCTCCC).

In a next step, in-vitro RNA transcription with subsequent base-specific cleavage using RNase A was performed. This procedure resulted in fragmented RNA molecules of identical length. RNA molecules differed in their nucleotide composition due to bisulfite treatment. After sample preparation, a MALDI-TOF platform (Agena; MassArray 4) was used to process the probes. Resulting data from the mass spectrometer was preprocessed using the EpiTYPER Analyser. Methylation status was quantified by analyzing the mass spectra.

We assessed methylation status regarding single $\mathrm{CpG}$ units (some $\mathrm{CpG}$ sites lay on the same RNA fragment and methylation status reflects the mean of all sites on this fragment). Boxplots for $\mathrm{CpG}$ units with analyzable methylation status are depicted in Fig. 2. Since we wanted to have a joint measure of SLC6A4 DNA methylation, we first analyzed the associations between all CpG sites and units (see the supplementary material, Table S1). Reliability across CpG sites was good ( $\alpha=$ $.82)$. However, there were very low correlation coefficients between some of the CpG units. Therefore, we performed a Principal Component Analysis (PCA) to extract the most important independent factors for SLC6A4 methylation. The Kaiser-Meyer-Olkin measure of sampling adequacy was .698 , representing a relatively good factor analysis, and Bartlett's test of sphericity was 

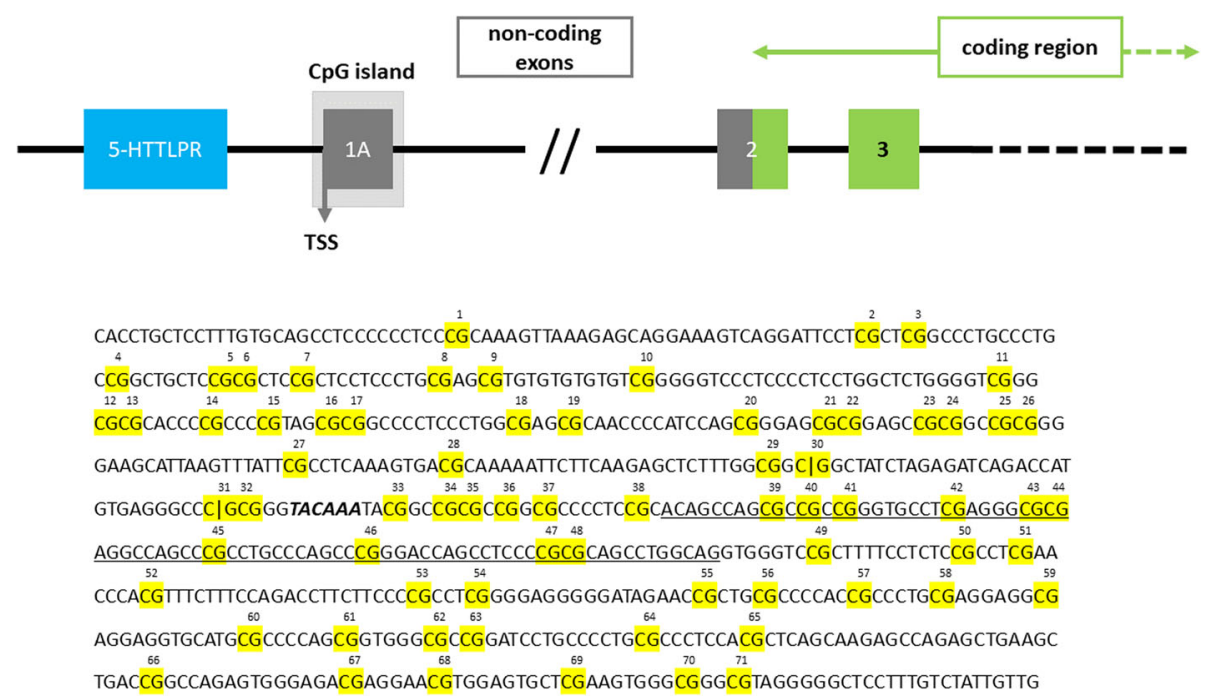

Fig. 1 Schematic representation of the SLC6A4 gene. The position of the examined CpG island is marked by a light grey box. CpG sites are marked in yellow color and numbered. Bold and italic letters mark the putative TATA-box. Exon 1A is underlined

significant $(p<.001)$. Only factors explaining more than $10 \%$ of variance in the methylation data were considered [67], resulting in a two factor solution. The two factors accounted for $31.44 \%$ of the total variance in SLC6A4 methylation. Among the factor solutions, the varimax-rotated two-factor solution yielded the most interpretable solution (factor 1: centric to terminal CpG units of the investigated region; factor 2: anterior and centric $\mathrm{CpG}$ units), and most $\mathrm{CpG}$ units loaded highly on only one of the two factors (for further information and the varimax-rotated two factor solution see supplementary material Tables S2). These two factors of SLC6A4 methylation were entered in the statistical analyses.

\section{Statistical analysis}

Statistical analyses were conducted using $R$ [68] with the packages psych [69], and ggplot2 [70] as well as IBM SPSS Statistics for Windows, version 25. To control for confounding variables associated with SLC6A4 methylation or age at depression onset, we tested associations between potential covariates (age, BMI, substance use, dose equivalents of antidepressants and neuroleptics) and SLC6A4 methylation as well as age at depression onset using Spearman's correlation coefficients. Next, we investigated sex differences and differences between inpatients without and with a family history of psychiatric disorders performing Welch's $t$-tests (note that U-tests provided similar results). Thereafter, we calculated

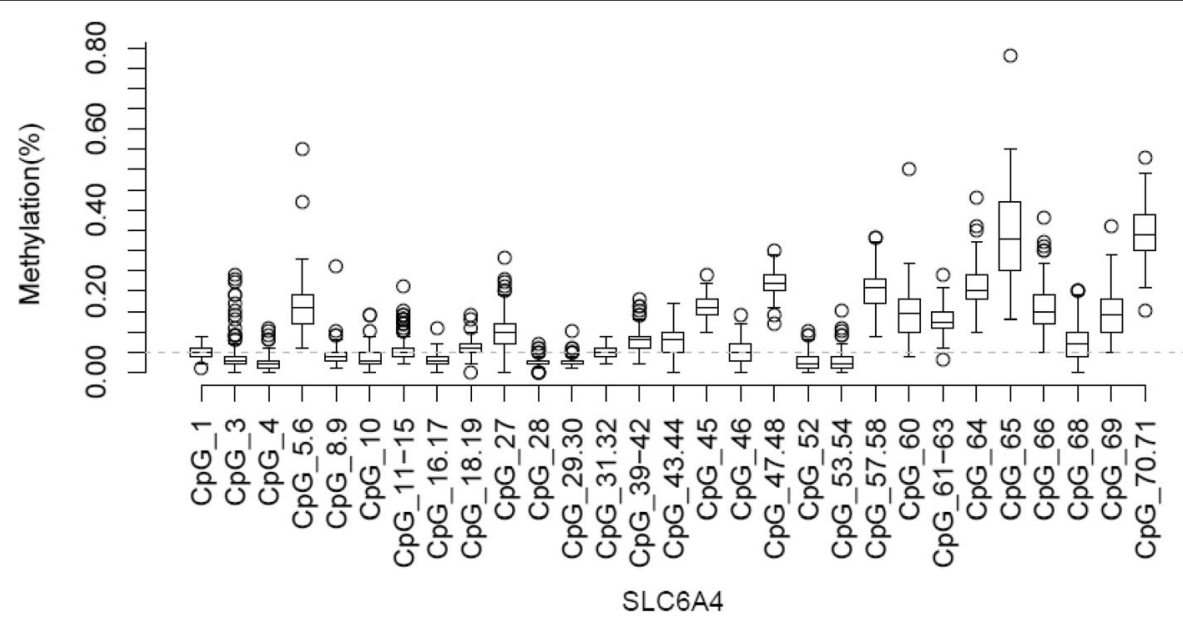

Fig. 2 Boxplots for the methylation status of the examined CpG Sites in the SLC6A4 CpG island 
partial Spearman's correlation coefficients between the variables of interest controlling for potentially confounding variables. In detail, we examined associations between depression severity (BDI-II and MADRS), CLEQ score, SEEKING, SADNESS, age at depression onset as well as both factors of SLC6A4 methylation. In addition, we wanted to explore, which of the examined variables is a predictor of depression onset and whether interactions between sex, 5-HTTLPR genotype and SLC6A4 methylation affect early depression onset. Thus, we performed a stepwise hierarchical linear regression analysis with sex, CLEQ, SEEKING, SADNESS, 5-HTTLPR genotype (L/L vs. S+), SLC6A4 factor 1, SLC6A4 factor 2 as well as interactions between DNA methylation and sex as wells as 5-HTTLPR genotype as predictors in the full model. Age at depression onset was the dependent variable. We used an automatic stepwise model selection by the Akaike information criterion $(A I C)$ allowing for iteratively adding and removing predictors. BenjaminiHochberg correction was used controlling false discovery rate (FDR) [71]. Statistical significance was determined at $p<.05$; all tests were two-tailed.

\section{Results}

\section{Control analyses}

Age and BMI were significantly associated with SLC6A4 methylation and/or age at depression onset (Table 1). Therefore, age and BMI were added as covariates in all analyses reported below. 5-HTTLPR genotype groups did not differ in SLC6A4 methylation neither for methylation factor $1\left(\mathrm{~L}_{\mathrm{A}} \mathrm{L}_{\mathrm{A}}: n=35, M=0.06, S D=1.04 ; \mathrm{S} / \mathrm{L}_{\mathrm{G}}\right.$ : $n=91, M=-0.08, S D=0.93 ; t(56.06)=0.68, p=.50)$ nor for methylation factor $2\left(\mathrm{~L}_{\mathrm{A}} \mathrm{L}_{\mathrm{A}}: n=35, M=-0.22\right.$, $S D=0.09 ; \mathrm{S} / \mathrm{L}_{\mathrm{G}}: n=91, M=0.09, S D=1.08 ; t(73.96)=$ $-1.62, p=.11)$ nor for age at depression onset $\left(\mathrm{L}_{\mathrm{A}} \mathrm{L}_{\mathrm{A}}\right.$ :
$M=26.02, S D=12.72 ; \mathrm{S} / \mathrm{L}_{\mathrm{G}}: M=25.78, S D=13.44 ; t$ $(80.49)=0.11, p=.92)$. There were no significant genotype differences in any of the investigated variables even before controlling FDR (see supplementary material Table S4).

\section{Sex differences and differences between inpatients without and with a family history of psychiatric disorders} The investigation of sex differences revealed women to score higher than men with respect to the primary emotion SADNESS. Furthermore, women showed higher methylation of centric to terminal $\mathrm{CpG}$ sites as indexed by factor 1 of SLC6A4 methylation. There were no sex differences in any of the other variables. Exact descriptive and inferential statistics can be found in (Table 2). There were no significant differences between inpatients without and inpatients with a family history of psychiatric disorders after FDR correction (Table 3).

\section{Correlation analyses}

Partial Spearman's correlation analyses of the whole sample (Table 4) showed that after FDR correction there was a significantly positive association between CLEQ and depression severity (with both BDI-II and MADRS) as well as SADNESS. In addition, the CLEQ was significantly negatively associated with age at depression onset. SEEKING was significantly negatively associated with depression severity (with both BDI-II and MADRS) and SADNESS. SADNESS on the other hand was significantly positively associated with depression severity (with both BDI-II and MADRS) and significantly negatively associated with age at depression onset. Besides the significantly negative associations between age at onset and CLEQ as well as SADNESS, age at onset was also

Table 1 Spearman's correlation coefficients between SLC6A4 methylation as well as age at onset and potentially confounding variables

\begin{tabular}{lllll}
\hline & & SLC6A4 factor 1 & SLC6A4 factor 2 & age at onset \\
\hline Age & $r$ & 0.41 & 0.21 & 0.60 \\
BMI & $p$ & 0.000 & 0.019 & 0.000 \\
& $r$ & 0.13 & 0.15 & 0.21 \\
alcohol (grams/day) & $p$ & 0.159 & 0.105 & 0.012 \\
& $r$ & 0.01 & 0.01 & 0.07 \\
cigarettes/day & $p$ & 0.904 & 0.931 & 0.415 \\
& $r$ & -0.05 & -0.17 & -0.04 \\
DE antidepressants & $p$ & 0.604 & 0.052 & 0.660 \\
& $r$ & -0.14 & 0.10 & 0.13 \\
DE neuroleptics & $p$ & 0.165 & 0.324 & 0.149 \\
& $r$ & 0.05 & -0.14 & 0.05 \\
\hline
\end{tabular}

DE dose equivalents. Spearman's correlation coefficients. P-values not FDR corrected 
Table 2 Sex differences in the covariates and variables of interest

\begin{tabular}{|c|c|c|c|c|c|c|c|c|c|}
\hline & $n(m / f)$ & $M_{\text {men }}$ & $S D_{\text {men }}$ & $M_{\text {women }}$ & $S D_{\text {women }}$ & $t$ & $d f$ & $p_{B H}$ & $d$ \\
\hline Age & $51 / 95$ & 39.29 & 13.98 & 38.44 & 14.46 & 0.35 & 105.44 & 0.785 & 0.06 \\
\hline BMI & $51 / 95$ & 26.48 & 4.68 & 25.66 & 7.02 & 0.85 & 137.30 & 0.557 & 0.14 \\
\hline alcohol (grams/day) & $49 / 89$ & 7.72 & 20.76 & 2.06 & 6.69 & 1.86 & 53.55 & 0.193 & 0.37 \\
\hline cigarettes/day & $50 / 94$ & 6.96 & 10.53 & 4.62 & 7.18 & 1.41 & 73.81 & 0.306 & 0.26 \\
\hline DE antidepressants & $46 / 78$ & 41.66 & 31.08 & 33.81 & 26.93 & 1.43 & 84.04 & 0.306 & 0.27 \\
\hline DE neuroleptics & $50 / 93$ & 22.50 & 44.10 & 27.15 & 49.54 & -0.58 & 110.86 & 0.634 & -0.10 \\
\hline BDI-II & $50 / 89$ & 29.61 & 12.16 & 33.74 & 10.58 & -2.01 & 90.44 & 0.162 & -0.36 \\
\hline MADRS & $51 / 95$ & 24.00 & 9.64 & 25.66 & 9.95 & -0.98 & 105.18 & 0.534 & -0.17 \\
\hline CLEQ & $48 / 90$ & 7.71 & 5.25 & 7.82 & 4.37 & -0.13 & 82.16 & 0.898 & -0.02 \\
\hline SEEKING & $48 / 89$ & 2.38 & 0.37 & 2.43 & 0.40 & -0.74 & 104.04 & 0.569 & -0.13 \\
\hline SADNESS & $49 / 89$ & 2.80 & 0.39 & 3.02 & 0.35 & -3.17 & 91.05 & 0.028 & -0.57 \\
\hline age at onset & $51 / 95$ & 29.43 & 14.31 & 23.80 & 12.05 & 2.39 & 88.47 & 0.089 & 0.43 \\
\hline SLC6A4 factor 1 & $46 / 81$ & -0.38 & 0.97 & 0.13 & 0.91 & -2.95 & 88.79 & 0.028 & -0.55 \\
\hline SLC6A4 factor 2 & $46 / 81$ & 0.20 & 1.16 & -0.12 & 0.95 & 1.58 & 79.43 & 0.280 & 0.30 \\
\hline
\end{tabular}

Welch's $t$-test

significantly negatively associated with depression severity (BDI-II only).

Analysis of both sexes separately revealed similar result patterns. However, the significantly positive associations between CLEQ and depression severity as well as SADNESS was present only in men. In addition, men as compared to women showed medium size negative associations between age at depression onset and depression severity. This association was significant for the MADR S. In women, we found a significantly positive association of medium size between methylation factor 2 of SLC6A4 and depression severity (MADRS only). This association was not present in men.
For associations between single $\mathrm{CpG}$ sites/units and depression severity, CLEQ, SEEKING, SADNESS and age at onset, see the Supplementary Material (Table S3).

\section{Hierarchical linear regression analysis}

In order to determine which predictors explain a significant amount of variance considering age at depression onset, we performed a stepwise regression analysis (both directions). We included age and BMI as covariates and sex, CLEQ, SEEKING, SADNESS, 5-HTTLPR genotype, SLC6A4 factor 1, SLC6A4 factor 2 as well as interactions between DNA methylation, sex and 5-HTTLPR genotype as predictors in the full model. All metric variables

Table 3 Differences between inpatients without (no) and with (yes) family history of psychiatric disorders

\begin{tabular}{llllllllll}
\hline & $\boldsymbol{n}$ (no/yes) & $\boldsymbol{M}_{\boldsymbol{n o}}$ & $\boldsymbol{S D}_{\boldsymbol{n o}}$ & $\boldsymbol{M}_{\text {yes }}$ & $\boldsymbol{S D}_{\text {yes }}$ & $\boldsymbol{t}$ & $\boldsymbol{d f}$ & $\boldsymbol{p}_{\boldsymbol{B H}}$ & $\boldsymbol{d}$ \\
\hline Age & $44 / 83$ & 41.68 & 12.93 & 37.51 & 14.31 & 1.67 & 95.74 & 0.453 & 0.31 \\
BMI & $44 / 83$ & 26.96 & 6.56 & 25.60 & 6.18 & 1.13 & 83.27 & 0.453 & 0.21 \\
alcohol (grams/day) & $42 / 78$ & 7.25 & 22.07 & 2.85 & 7.78 & 1.25 & 46.56 & 0.453 & 0.27 \\
cigarettes/day & $44 / 81$ & 4.80 & 6.70 & 6.03 & 9.61 & -0.84 & 115.37 & 0.566 & -0.15 \\
DE antidepressants & $35 / 73$ & 35.05 & 21.48 & 37.43 & 31.67 & -0.46 & 93.71 & 0.697 & -0.09 \\
DE neuroleptics & $43 / 81$ & 24.42 & 51.90 & 29.32 & 47.73 & -0.52 & 79.75 & 0.697 & -0.10 \\
BDI-II & $43 / 79$ & 30.21 & 10.78 & 33.09 & 12.08 & -1.35 & 95.12 & 0.453 & -0.25 \\
MADRS & $44 / 83$ & 23.27 & 9.49 & 25.59 & 9.77 & -1.30 & 90.05 & 0.453 & -0.24 \\
CLEQ & $43 / 80$ & 7.28 & 4.33 & 8.21 & 5.19 & -1.06 & 100.09 & 0.453 & -0.20 \\
SEEKING & $42 / 80$ & 2.41 & 0.31 & 2.43 & 0.42 & -0.33 & 107.29 & 0.745 & -0.06 \\
SADNESS & $43 / 80$ & 2.88 & 0.40 & 2.96 & 0.38 & -1.11 & 82.57 & 0.453 & -0.21 \\
age at onset & $44 / 83$ & 29.43 & 13.12 & 23.75 & 12.74 & 2.35 & 85.53 & 0.294 & 0.44 \\
SLC6A4 factor 1 & $37 / 72$ & 0.04 & 1.10 & -0.06 & 0.83 & 0.48 & 58.08 & 0.697 & 0.10 \\
SLC6A4 factor 2 & $37 / 72$ & 0.22 & 0.99 & -0.17 & 1.06 & 1.85 & 77.27 & 0.453 & 0.37 \\
\hline
\end{tabular}


Table 4 Partial Spearman's correlation coefficients (below the diagonal) and p-values (above the diagonal for the whole sample and both sexes separately

\begin{tabular}{|c|c|c|c|c|c|c|c|c|}
\hline $\begin{array}{l}\text { whole sample } \\
(N=146)\end{array}$ & BDI-II & MADRS & CLEQ & SEEKING & SADNESS & age at onset & SLC6A4 factor 1 & SLC6A4 factor 2 \\
\hline$\overline{\mathrm{BDI}-\mathrm{II}}$ & & $<0.001$ & $<0.001$ & $<0.001$ & $<0.001$ & 0.025 & 0.700 & 0.700 \\
\hline MADRS & $0.62^{* * *}$ & & 0.035 & $<0.001$ & $<0.001$ & 0.160 & 0.700 & 0.123 \\
\hline CLEQ & $0.33^{* * *}$ & $0.21^{*}$ & & 0.700 & 0.011 & 0.001 & 0.869 & 0.598 \\
\hline SEEKING & $-0.32^{* * *}$ & $-0.32^{* * *}$ & 0.05 & & 0.008 & 0.102 & 0.998 & 0.416 \\
\hline SADNESS & $0.49^{* * *}$ & $0.42^{* * *}$ & $0.25^{*}$ & $-0.26^{* *}$ & & $<0.001$ & 0.998 & 0.755 \\
\hline age at onset & $-0.22^{*}$ & -0.14 & $-0.31^{* *}$ & 0.17 & $-0.35^{* * *}$ & & 0.220 & 0.700 \\
\hline SLC6A4 factor 1 & 0.06 & 0.05 & 0.02 & -0.00 & -0.00 & -0.14 & & 0.372 \\
\hline $\begin{array}{l}\text { SLC6A4 factor } 2 \\
\text { women } \\
(\boldsymbol{n}=\mathbf{9 5})\end{array}$ & -0.05 & 0.17 & -0.08 & 0.10 & 0.04 & 0.05 & -0.11 & \\
\hline BDI-II & & $<0.001$ & 0.065 & 0.006 & $<0.001$ & 0.437 & 0.479 & 0.998 \\
\hline MADRS & $0.66^{* * *}$ & & 0.562 & 0.012 & $<0.001$ & 0.851 & 0.851 & 0.026 \\
\hline CLEQ & 0.25 & 0.10 & & 0.826 & 0.769 & 0.042 & 0.361 & 0.479 \\
\hline SEEKING & $-0.36^{* *}$ & $-0.33^{*}$ & 0.05 & & 0.026 & 0.361 & 0.945 & 0.479 \\
\hline SADNESS & $0.47^{* * *}$ & $0.47^{* * *}$ & 0.07 & $-0.30^{* *}$ & & 0.049 & 0.479 & 0.785 \\
\hline age at onset & -0.14 & -0.04 & $-0.27^{*}$ & 0.16 & $-0.26^{*}$ & & 0.769 & 0.907 \\
\hline SLC6A4 factor 1 & -0.13 & -0.04 & -0.17 & 0.01 & -0.13 & 0.07 & & 0.945 \\
\hline SLC6A4 factor 2 & -0.00 & $0.31^{*}$ & -0.12 & 0.13 & 0.06 & 0.03 & -0.02 & \\
\hline $\begin{array}{l}\text { men } \\
(n=51)\end{array}$ & & & & & & & & \\
\hline BDI-II & & $<0.001$ & 0.014 & 0.180 & 0.006 & 0.181 & 0.829 & 0.956 \\
\hline MADRS & $0.61^{* * *}$ & & 0.011 & 0.124 & 0.047 & 0.047 & 0.956 & 0.956 \\
\hline CLEQ & $0.45^{*}$ & $0.46^{*}$ & & 0.975 & 0.001 & 0.026 & 0.401 & 0.956 \\
\hline SEEKING & -0.27 & -0.30 & 0.00 & & 0.578 & 0.101 & 0.962 & 0.956 \\
\hline SADNESS & $0.50^{* *}$ & $0.36^{*}$ & $0.56^{* *}$ & -0.15 & & 0.014 & 0.956 & 0.703 \\
\hline age at onset & -0.26 & $-0.36^{*}$ & $-0.40^{*}$ & 0.32 & $-0.43^{*}$ & & 0.233 & 0.956 \\
\hline SLC6A4 factor 1 & 0.09 & 0.05 & 0.20 & -0.02 & -0.05 & -0.25 & & 0.616 \\
\hline SLC6A4 factor 2 & -0.02 & -0.02 & 0.06 & 0.04 & 0.12 & -0.03 & -0.14 & \\
\hline
\end{tabular}

Covariates: age and BMI. FDR corrected $p$-values (for each sample separately). ${ }^{* * *} p<.001,{ }^{* *} p<.01,{ }^{*} p<.05$

Table 5 Final model of the stepwise regression analysis with age at onset as dependent variable

\begin{tabular}{lllll}
\hline Predictor & $\boldsymbol{b}$ & $\boldsymbol{S E}$ & $\boldsymbol{t}$ & $\boldsymbol{p}$ \\
\hline (Intercept) & 0.49 & 0.22 & 2.21 & 0.029 \\
Age & 0.69 & 0.06 & 10.75 & 0.000 \\
BMI & -0.06 & 0.06 & -0.93 & 0.356 \\
Sex & -0.30 & 0.13 & -2.30 & 0.024 \\
CLEQ & -0.16 & 0.06 & -2.61 & 0.010 \\
SEEKING & 0.13 & 0.06 & 2.09 & 0.039 \\
SADNESS & -0.11 & 0.07 & -1.57 & 0.119 \\
\hline
\end{tabular}

The covariates age and BMI were included by default were standardized. The Akaike information criterion (AIC) indicated the selection of a model including sex, SLEs, SEEKING and SADNESS for the prediction of age at depression onset. This model is shown in Table 5 and explained a significant amount of variance in age at depression onset $\left(R^{2}=0.60, F(6,110)=29.44, p<.000001\right)$. Higher age at the time of measurement was associated with lower age at depression onset. Female sex and experience of SLEs were associated with lower age at depression onset. Higher SEEKING was associated with higher age at depression onset.

\section{Discussion}

In the present study, we examined the role of SLEs, primary emotions, DNA-methylation of SLC6A4 and depression severity for depression onset. We assumed 
early-onset depression to be associated with more SLEs, less SEEKING, higher SADNESS and higher depression severity. We also assumed an association between age at onset and SLC6A4 methylation. In addition, we wanted to examine which variables might serve as best predictors explaining a significant amount of variance in age at depression onset. Basing on previous findings, we also investigated possible SLC6A4 methylation $\times$ sex $\times 5$ HTTLPR interactions in the investigation of depression onset.

As expected, we found depression onset to be negatively associated with SLEs after controlling for age and BMI. This is in line with previous results of more SLEs in patients with early as compared to patients with adult-onset depression [13] and with the association of stress with first depression onset [72, 73]. The association between stress and depression is a well-established finding that has been documented for various stressors $[74,75]$, recent and early SLEs [76, 77] and in a variety of samples with different age groups $[53,78,79]$. In the adolescent period, the individual could be especially vulnerable to stressors since this period is considered important for the organization of behavioral and endocrine responses to stress. In addition, the maturation of brain systems involved in the control of the HPA-axis takes place during this transition period [80]. It is possible that inpatients with an early depression onset had an adverse environment in early developmental stages [81]. However, as data about early life adversities was not available in the present sample, this hypothesis needs to be tested in future studies.

SLEs in these early developmental stages could be a predictor of current depressive symptom severity because of their long lasting effects on the bodily stress system. Daskalakis and colleagues [82] suggest a threehit concept of vulnerability and resilience in the face of early life adversity: They postulate an interaction of genetic factors (hit-1) with early environmental factors (hit2) to be reflected in epigenetic modifications and altered endocrine regulations. This interaction programs gene expression patterns, which are relevant for an evolving phenotype during brain development. The emerging phenotype with altered stress axis regulation and sensitivity is exposed to the later-life environment (hit-3). Depending on the type of later-life challenge, the individual is either vulnerable or resilient to the development of psychiatric symptoms [82]. The three-hit concept provides a framework for the interpretation of early as well as later-life SLEs' association with depressive symptoms [83] and takes into consideration why some individuals develop depression after the experience of early adversity and some do not. This in turn is an explanation for the finding of a medium size positive association between
SLEs and depressive symptoms, which is in line with previous studies [13].

High SADNESS scores were associated with younger age at depression onset. This is in line with previous studies reporting high scores on the personality dimension neuroticism to be a vulnerability factor for early depression onset [13, 14]. However, after taking into account other predictors, SADNESS did not explain a significant amount of variance in age at depression onset. An explanation could be that there are associations between SLEs and SADNESS, between SEEKING and SADNESS and between sex and SADNESS. Thus, SADN ESS shares variance with three of the other predictors included in the final model. However, SADNESS was still included in the model with the lowest AIC.

While there was a small to medium size positive correlation coefficient between SEEKING and age at depression onset, this association was not significant. In the regression model predicting age at onset, however, SEEKING explained a significant amount of variance in the dependent variable beyond the variance explained by other predictors. Thus, looking at the model best suited for the prediciton of age at depression onset, our findings are in line with the theory of depression development by Watt and Panksepp [16]. Therefore, we want to give a possible explanation for our findings with reference to their theory: If an individual has high SADNESS scores arising from social loss or defeat [17], low reward-SEEKING protects against new social losses or defeats. However, social isolation also prevents positive social experiences, which in turn can be considered a social loss if it is a permanent condition. This vicious circle might culminate in a major depressive episode in line with Lewinsohn's [84] social reinforcement theory. Therefore, SLEs, SADNESS and SEEKING might serve for early identification of individuals at risk of developing depression. Since the ANPS provides the opportunity for detecting individuals scoring high on two main symptoms of depression, depressive mood and loss of interest/energy, it could be better suited for the detection of individuals at risk for depression development than examining Neuroticism only. Of note, Neuroticism represents a super-factor, being not only associated with SADNESS, but also FEAR and ANGER [20, 22]. In terms of Affective Neuroscience theory, SADNESS should be the core dimension to understand depression, although strong overlaps with FEAR have been observed aswell [23]. At this point we emphasize that it is not clear whether associations between age at onset or depression severity and SEEKING as well as SADNESS are an expression of primary emotions predisposing for depression or for depression having an impact on primary emotions. This needs to be evaluated using a longitudinal design. 
Our findings are not only in line with interventions used for the treatment of depression, they could additionally provide an evolution based and easy to understand explanation of why these interventions are effective. For instance, behavioral activation is an effective initial intervention for the treatment of depression [85]. This may be explained by an activation of the downregulated SEEKING system thereby enabling the patient to experience positive reinforcements [85]. In addition, psychodynamic therapies or the cognitive behavioral analysis system of psychotherapy (CBASP) focussing on the experience of past and current relationships could teach patients to become connected with the depressogenic consequences of their interpersonal behavior $[86,87]$ potentially counteracting an upregulated SADNESS system by enabling rewarding social interactions. In addition, we found female gender to be a risk factor for early age at depression onset, which is in line with previous studies on sex differences in depression development [88].

It is also worth mentioning that we discovered slightly different methylation patterns between the variables of interest when investigating men and women separately. The expected positive association between SLEs and SADNESS was found only in men. Further, the negative association between depression severity and SEEKING was only present in women. This could mean one of four things: for one, depressive symptoms in women could differ from depressive symptoms in men in line with previous findings [89]. Second, women could have different risk factors predisposing them for depression, e.g. a more strongly expressed shutdown following separation distress as proposed by Watt and Panksepp [16]. Third, depressive symptoms could have a different impact on primary emotions as a function of sex. Fourth, power was too low to detect the association in men (we could only investigate $n=51$ males compared to $n=95$ females), which is supported by the low to medium size negative association between SEEKING and depression severity found in men (BDI-II: $r=-0.27$, MADRS: $r=-$ 0.30). The finding of women scoring higher on SADN ESS than men is in line with previous studies reporting that women tend to naturally report higher neuroticism scores, especially in egalitarian societies [90].

Even though we did not find differences between inpatients without and with a family history of psychiatric disorders, psychiatric disorders in family members are an important factor associated with depression development and suicide [91, 92]. In addition, parents' psychiatric disorders could be stressors affecting epigenetic mechanisms in the offspring [93]. A possible explanation for the nonsignificant results regarding this variable could be that we collected data on family psychiatric history by means of self-report and that patients may not correctly assess the psychopathology of family members.

Contradictory to our expectations, in the whole sample, SLC6A4 methylation was associated with neither of the investigated variables. When looking at women and men separately, we found one significantly positive association between SLC6A4 methylation factor 2 and depression severity in women. This association is in line findings of higher SLC6A4 methylation being associated with depression severity $[42,44]$. There are, however, also studies reporting negative associations between SLC6A4 methylation and depression severity [42, 43, 45-47]. Depending on the specific CpG site or cluster of CpG sites examined, there may be positive or negative associations between SLC6A4 methylation, personality and depression. In line with a previous study [94] we found women to have higher SLC6A4 methylation of centric to terminal $\mathrm{CpG}$ sites as indexed by methylation factor 1 . Since methylation of factor 1 is not associated with any of the investigated variables, this sex difference in SLC6A4 methylation does not seem to be related to SLEs or depressive symptoms. Furthermore, SLC6A4 methylation was not included in the model prediciting age at depression onset. Therefore, SLC6A4 methylation does not seem strongly related to depression, which questions the usefulness of SLC6A4 methylation as biomarker for depression onset. But again, our insights are also limited by the rather small sample of patients investigated. Beyond that, it is possible that SLC6A4 methylation was associated with depression severity at the time of onset of the first depressive episode. Furthermore, it is possible that SLC6A4 methylation differs between individuals developing a depressive episode and individuals that do not develop a depressive episode. Another interesting question is whether and when a stressor affects SLC6A4 methylation. It is possible that depression itself is stressful [95] and leaves traces in epigenetic signatures of the serotonin system of affected individuals which would make it more difficult to distinguish epigenetic mechanisms involved in depression development from signatures of depression itself. Therefore, prospective studies investigating epigenetic signatures before and after depression onset as well as during the course of the disorder are needed.

We did not find any significant association between the examined variables and 5-HTTLPR genotype (see supplementary material Table S4). Even though our sample size is too small for making conclusions on the presence or absence of a genotype effect, this is in line with the meta-analysis by Culverhouse and colleagues [32], who did not find strong evidence of a main effect or interaction of 5-HTTLPR in the development of depression. Overall, our findings do not support the notion of a strong linear association between SLC6A4 
regulation and depression. However, there could still be differences in SLC6A4 methylation when comparing inpatients suffering from depression to healthy controls. Nevertheless, SLC6A4 appears to be associated with depression, but in a more complex fashion. There might be moderating factors other than sex and 5-HTTLPR that make it difficult to understand the exact function of SLC6A4 in the development and maintenance of depression. However, if the lack of a direct association between SLC6A4 or the 5-HTT and depression replicates in future studies, the mechanism of action of SSRIs and the role of the serotonin system in the development and maintenance of depression as a whole would need to be re-discussed. After all, it has been shown that neurogenesis mediates some beneficial effects of antidepressant treatment [96]. Additionally, first steps towards a joint explanation of the effectiveness of different kinds of antidepressants have already been taken and point towards a role of sphingolipid-controlled autophagy as an important target for antidepressive treatment [97]. A better understanding of the mechanism of action of antidepressants and the role of the 5-HTT in depression and antidepressive treatment could clarify the question of whether current antidepressants are effective in the treatment of depression and how they exert their antidepressive effect [98-101].

Some limitations need to be considered when interpreting the results of our study. First, methylation in whole blood samples is only a proxy for epigenetic profiles in brain tissue. Second, we cannot draw conclusions regarding the functionality of the observed alterations in SLC6A4 methylation since we did neither assess mRNA nor 5-HTT levels. Third, statistical power could be too low to detect associations between SLC6A4 methylation and age at depression onset or depression severity. A post-hoc power analysis, however, revealed that given our total sample size of $N=146$ and $\alpha=.05$ (two-tailed) power to detect a medium-sized effect [102] was determined to be 0.97 . However, we cannot rule out the possibility that there are small associations between SLC6A4-methylation and age at depression onset. Fourth, we did not assess the timing of the stressor, which is why we cannot differentiate between early and late life stressors. Last, we assessed depression onset retrospectively. In future, studies with prospective longitudinal designs are needed to confirm and extend our results.

Taken together, we provide evidence that young age at depression onset is associated with depressive symptom severity. In addition, we found that a considerable amount of variance in depression onset can be explained by sex, the experience of SLEs and personality traits comprising high SADNESS and low SEEKING. Thus, our work can serve as starting point for future studies using a longitudinal design for the investigation of the causal role of sex, primary emotions, SLEs and epigenetic factors for depression development in young age. As the number of people suffering from depression rises, early identification of at-risk individuals is becoming increasingly important for establishing prevention interventions alleviating the burden that depression imposes on individuals, their social environment and society.

\section{Abbreviations}

5-HT: Serotonin; 5-HTT: Serotonin transporter; 5-HTTLPR: Serotonin transporter linked polymorphic region; AIC: Akaike information criterion; ANPS: Affective Neuroscience Personality Scales; BDI-II: Beck Depression Inventory; BMI: Body Mass Index; CLEQ: Critical Life Events Questionnaire; CpG: Cytosine-phosphate-guanine dinucleotides; DE: Dose equivalents; FDR: False discovery rate; MADRS: Montgomery Asberg Depression Rating Scale; MDD: Major Depressive Disorder; SLE: Stressful life event; SSRI: Selective serotonin reuptake inhibitor

\section{Supplementary Information}

The online version contains supplementary material available at https://doi. org/10.1186/s12888-021-03166-6.

Additional file 1

Acknowledgements

None

Authors' contributions

S.S., C.M., M.K. and the GenEmo Research group designed the present study. S.S. analyzed the data and wrote the first draft of the manuscript. C.M., M.K., K.W-M. and C.S-L. commented on and improved previous versions of the manuscript. All authors contributed to and approved the manuscript.

\section{Funding}

Open Access funding enabled and organized by Projekt DEAL.

Availability of data and materials

The datasets analyzed during the current study are not publicly available since the authors do not have permission to publish the data. However, data are available from the corresponding author on reasonable request.

\section{Declarations}

Ethics approval and consent to participate

All procedures performed in this study were in accordance with the standards of the ethics committee of Ulm University, Ulm, Germany and with the 1964 Helsinki declaration and its later amendments. The experimental protocols were approved by the ethics committee of Ulm University, UIm, Germany. Written informed consent of the participants was obtained after the procedures had been fully explained.

Consent for publication

Not applicable.

Competing interests

There are no competing financial interests to be disclosed.

\section{Author details}

${ }^{1}$ Department of Psychiatry and Psychotherapy III, UIm University, UIm, Germany. ${ }^{2}$ Institute of Psychology and Education, Department of Molecular Psychology, Ulm University, Ulm, Germany. 
Received: 8 December 2020 Accepted: 12 March 2021

Published online: 25 March 2021

\section{References}

1. Mojtabai R, Olfson M, Han B. National Trends in the Prevalence and Treatment of Depression in Adolescents and Young Adults. Pediatrics [Internet]. 2016 [cited 2019 Sep 2];138(6):e20161878. Available from: http:// www.ncbi.nlm.nih.gov/pubmed/27940701.

2. Milaneschi Y, Lamers F, Peyrot WJ, Abdellaoui A, Willemsen G, Hottenga J-J, et al. Polygenic dissection of major depression clinical heterogeneity. Mol Psychiatry [Internet]. 201630 [cited 2019 Oct 7];21(4):516-522. Available from: http://www.nature.com/articles/mp201586

3. Mullins N, Lewis CM. Genetics of Depression: Progress at Last. Vol. 19, Current Psychiatry Reports. Current Medicine Group LLC 1. 2017:1-7.

4. Montag C, Ebstein R, Jawinski P, Markett S. Molecular genetics in psychology and personality neuroscience: on candidate genes, genome wide scans, and new research strategies. Neurosci Biobehav Rev. 2020;118: 163-74. https://doi.org/10.1016/j.neubiorev.2020.06.020.

5. Hasin DS, Goodwin RD, Stinson FS, Grant BF. Epidemiology of major depressive disorder: Results from the National Epidemiologic Survey on Alcoholism and Related Conditions. Vol. 62, Archives of General Psychiatry. Am Med Assoc. 2005:1097-106.

6. Weissman M, Bland RC, Canino G, Faravelli C, Greenwald S, Hwu HG, et al. Cross-National Epidemiology of major depression and bipolar disorder. J Am Med Assoc. 1996;276(4):293-9. https://doi.org/10.1001/jama.1996.0354 0040037030

7. Kendler KS, Gatz M, Gardner CO, Pedersen NL. A Swedish national twin study of lifetime major depression. Am J Psychiatry. 2006;163(1):109-14. https://doi.org/10.1176/appi.ajp.163.1.109.

8. Kendler KS, Gardner CO, Neale MC, Prescott CA. Genetic risk factors for major depression in men and women: similar or different heritabilities and same or partly distinct genes? Psychol Med. 2001;31(4):605-16. https://doi. org/10.1017/S0033291701003907.

9. Sullivan PF, Neale MC, Kendler KS. Genetic Epidemiology of Major Depression: Review and Meta-Analysis. Am J Psychiatry [Internet]. 2000 [cited 2018 Aug 14];157(10):1552-1562. Available from: http:// psychiatryonline.org/doi/abs/https://doi.org/10.1176/appi.ajp.157.10.1552

10. Power RA, Keers R, Ng MY, Butler AW, Uher R, Cohen-Woods S, et al. Dissecting the Genetic Heterogeneity of Depression Through Age at Onset. Am J Med Genet Part B Neuropsychiatr Genet [Internet]. 20121 [cited 2020 Apr 23];159B(7):859-868. Available from: http://doi.wiley.com/https://doi. org/10.1002/ajmg.b.32093

11. Gollan J, Raffety B, Gortner E, Dobson K. Course profiles of early- and adult-onset depression. J Affect Disord. 2005;86(1):81-6. https://doi.org/10.1016/j.jad.2004.12.009.

12. Parker G, Roy K, Hadzi-Pavlovic D, Mitchell P, Wilhelm K. Distinguishing early and late onset non-melancholic unipolar depression. J Affect Disord. 2003; 74(2):131-8. https://doi.org/10.1016/S0165-0327(02)00002-2.

13. Korten NCM, Comijs HC, Lamers F, Penninx BWJH. Early and late onset depression in young and middle aged adults: differential symptomatology, characteristics and risk factors? J Affect Disord. 2012;138(3):259-67. https:// doi.org/10.1016/j.jad.2012.01.042.

14. Kercher AJ, Rapee RM, Schniering CA. Neuroticism, life events and negative thoughts in the development of depression in adolescent girls. J Abnorm Child Psychol. 2009;37(7):903-15. https://doi.org/10.1007/s10802-009-9325-1.

15. Gade A, Kristoffersen M, Kessing LV. Neuroticism in Remitted Major Depression: Elevated with Early Onset but Not Late Onset of Depression. Psychopathology [Internet]. 201511 [cited 2020 Aug 18];48(6):400-407. Available from: https://www.karger.com/Article/FullText/440813

16. Watt DF, Panksepp J. Depression: An Evolutionarily Conserved Mechanism to Terminate Separation Distress? A Review of Aminergic, Peptidergic, and Neural Network Perspectives. Neuropsychoanalysis [Internet]. 2009 Jan [cited 2019 Jun 24];11(1):7-51. Available from: http://www.tandfonline.com/doi/ abs/https://doi.org/10.1080/15294145.2009.10773593

17. Panksepp J, Watt DF. Why Does Depression Hurt? Ancestral Primary-Process Separation-Distress (PANIC/GRIEF) and Diminished Brain Reward (SEEKING) Processes in the Genesis of Depressive Affect. Psychiatry Interpers Biol Process [Internet]. 20118 [cited 2018 Jul 19];74(1):5-13. Available from: http://guilfordjournals.com/doi/https://doi.org/10.1521/psyc.2011.74.1.5

18. Panksepp J. A critical role for "affective neuroscience" in resolving What is basic about basic emotions. Psychol Rev. 1992:99(3):554-60. https://doi. org/10.1037/0033-295X.99.3.554.
19. Davis $\mathrm{KL}$, Montag C. Selected principles of pankseppian affective neuroscience. Front Neurosci [Internet]. 201917 [cited 2019 Feb 5];12:1025. Available from: https://www.frontiersin.org/article/https://doi.org/10.3389/ fnins.2018.01025/full

20. Montag C, Panksepp J. Primary emotional systems and personality: An evolutionary perspective. Front Psychol [Internet]. 201711 [cited 2018 Jul 17];8:464. Available from: http://journal.frontiersin.org/article/https://doi. org/10.3389/fpsyg.2017.00464/full

21. Montag C, Panksepp J. Personality Neuroscience: Why It Is of Importance to Consider Primary Emotional Systems! In: Encyclopedia of Personality and Individual Differences [Internet]. Springer International Publishing; 2020 [cited 2020 Aug 18]. p. 3830-40. Available from: https://link.springer.com/ referenceworkentry/https://doi.org/10.1007/978-3-319-24612-3_1338

22. Montag C, Davis KL. Affective neuroscience theory and personality: An update. Personal Neurosci [Internet]. 201810 [cited 2019 Feb 5];1:e12. Available from: https://www.cambridge.org/core/product/identifier/S2513 98861800010X/type/journal_article

23. Montag C, Widenhorn-Müller K, Panksepp J, Kiefer M. Individual differences in Affective Neuroscience Personality Scale (ANPS) primary emotional traits and depressive tendencies. Compr Psychiatry [Internet]. 20171 [cited 2018 Jul 18];73:136-42. Available from: https://www.sciencedirect.com/science/a rticle/pii/S0010440X16303947

24. Heninger G, Delgado P, Charney D. The Revised Monoamine Theory of Depression: A Modulatory Role for Monoamines, Based on New Findings From Monoamine Depletion Experiments in Humans. Pharmacopsychiatry [Internet]. 199623 [cited 2018 Mar 23];29(01):2-11. Available from: http:// www.thieme-connect.de/DOI/DOI?https://doi.org/10.1055/s-2007-979535

25. Canli T, Lesch K-P. Long story short: The serotonin transporter in emotion regulation and social cognition [Internet]. Vol. 10, Nature Neuroscience. Nature Publishing Group; 2007 [cited 2020 Aug 18]. p. 1103-9. Available from: http://www.nature.com/natureneuroscience

26. Montag C, Reuter M. Disentangling the molecular genetic basis of personality: From monoamines to neuropeptides. Neurosci Biobehav Rev [Internet]. 20141 [cited 2019 Feb 5];43:228-239. Available from: https:// www.sciencedirect.com/science/article/pii/S0149763414000906

27. Palma-Gudiel $H$, Fañanás $L$. An integrative review of methylation at the serotonin transporter gene and its dialogue with environmental risk factors, psychopathology and 5-HTTLPR. Neurosci Biobehav Rev [Internet]. 20171 [cited 2019 Feb 14];72:190-209. Available from: https://www.sciencedirect. com/science/article/pii/S0149763416303797

28. Zhou Z, Zhen J, Karpowich NK, Law CJ, Reith MEA, Wang DN. Antidepressant specificity of serotonin transporter suggested by three LeUT-SSRI structures. Nat Struct Mol Biol. 2009;16(6):652-7. https://doi.org/10.1038/nsmb.1602.

29. Haase J, Killian A-M, Magnani F, Williams C. Regulation of the serotonin transporter by interacting proteins. Biochem Soc Trans. 2001;29(6):722-8. https://doi.org/10.1042/bst0290722.

30. Gelernter J, Pakstis AJ, Kidd KK. Linkage mapping of serotonin transporter protein gene SLC6A4 on chromosome 17. Hum Genet [Internet]. 1995 Jun [cited 2018 Mar 26];95(6):677-680. Available from: http://link.springer.com/ https://doi.org/10.1007/BF00209486

31. Lesch K-P, Balling U, Gross J, Strauss K, Wolozin BL, Murphy DL, et al. Organization of the human serotonin transporter gene. J Neural Transm [Internet]. 1994 Jun [cited 2018 Mar 26];95(2):157-162. Available from: http:// link.springer.com/https://doi.org/10.1007/BF01276434

32. Culverhouse RC, Saccone NL, Horton AC, Ma Y, Anstey KJ, Banaschewski T, et al. Collaborative meta-analysis finds no evidence of a strong interaction between stress and 5-HTTLPR genotype contributing to the development of depression. Mol Psychiatry [Internet]. 20184 [cited 2019 Jun 17];23(1): 133-142. Available from: http://www.nature.com/articles/mp201744

33. Heils A, Teufel A, Petri S, Stöber G, Riederer P, Bengel D, et al. Allelic Variation of Human Serotonin Transporter Gene Expression. J Neurochem [Internet]. 200223 [cited 2020 Apr 29];66(6):2621-2624. Available from: http://doi.wiley.com/https://doi.org/10.1046/j.1471-4159.1996.66062621.x

34. Bird AP. Perceptions of epigenetics. Nature [Internet]. 200724 [cited 2018 Aug 16];447(7143):396-398. Available from: http://www.nature.com/ doifinder/https://doi.org/10.1038/nature05913

35. Feil R, Fraga MF. Epigenetics and the environment: emerging patterns and implications. Nat Rev Genet [Internet]. 20124 [cited 2018 Mar 28];13(2):97109. Available from: http://www.nature.com/articles/nrg3142

36. Watt F, Molloy PL. Cytosine methylation prevents binding to DNA of a HeLa cell transcription factor required for optimal expression of the adenovirus 
major late promoter. Genes Dev [Internet]. 1988 [cited 2018 mar 22];2(9): 1136-1143. Available from: http://www.ncbi.nlm.nih.gov/pubmed/3192075.

37. Lim DHK, Maher ER. DNA methylation: a form of epigenetic control of gene expression. Obstet Gynaecol [Internet]. 2010 Jan [cited 2018 Jun 1];12(1):37-42. Available from: http://doi.wiley.com/https://doi.org/10.1576/toag.12.1.037.27556

38. Bird AP. CpG-rich islands and the function of DNA methylation. Nature [Internet]. 198615 [cited 2018 Mar 22];321(6067):209-13. Available from: http://www.nature.com/articles/321209a0

39. Nikolova YS, Koenen KC, Galea S, Wang C-M, Seney ML, Sibille E, et al. Beyond genotype: serotonin transporter epigenetic modification predicts human brain function. Nat Neurosci [Internet]. 20143 [cited 2018 Mar 26]; 17(9):1153-5. Available from: http://www.nature.com/articles/nn.3778

40. Duman EA, Canli T. Influence of life stress, 5-HTTLPR genotype, and SLC6A4 methylation on gene expression and stress response in healthy Caucasian males. Biol Mood Anxiety Disord [Internet]. 201514 [cited 2018 Mar 20];5(1): 2. Available from: http://www.biolmoodanxietydisord.com/content/5/1/2

41. Beach SRH, Brody GH, Todorov AA, Gunter TD, Philibert RA. Methylation at SLC6A4 is linked to family history of child abuse: An examination of the lowa Adoptee sample. Am J Med Genet Part B Neuropsychiatr Genet [Internet]. 20101 [cited 2018 Mar 26];153B(2):710-3. Available from: http:// doi.wiley.com/https://doi.org/10.1002/ajmg.b.31028

42. Zhao J, Goldberg J, Bremner JD, Vaccarino V. Association between promoter methylation of serotonin transporter gene and depressive symptoms: a monozygotic twin study. Psychosom Med [Internet]. 2013 [cited 2018 Feb 15];75(6):523-9. Available from: http://www.ncbi.n/m.nih.gov/pubmed/23 766378

43. Kang H-J, Kim J-M, Stewart R, Kim S-YS-W, Bae K-Y, Kim S-YS-W, et al. Association of SLC6A4 methylation with early adversity, characteristics and outcomes in depression. Prog Neuro-Psychopharmacology Biol Psychiatry [Internet]. 20131 [cited 2018 Mar 22];44:23-8. Available from: https://www. sciencedirect.com/science/article/pii/S0278584613000080

44. Kim J-M, Stewart R, Kang H-J, Kim S-W, Shin I-S, Kim H-R, et al. A longitudinal study of SLC6A4 DNA promoter methylation and poststroke depression. J Psychiatr Res [Internet]. 2013 [cited 2018 Feb 15];47(9):1222-7. Available from: http://www.ncbi.nlm.nih.gov/pubmed/23702251.

45. Kim J-M, Stewart R, Kim S-W, Yang S-J, Shin I-S, Kim Y-H, et al. Interactions Between Life Stressors and Susceptibility Genes (5-HTTLPR and BDNF) on Depression in Korean Elders. Biol Psychiatry [Internet]. 2007 Sep [cited 2018 Mar 28];62(5):423-8. Available from: http//linkinghub.elsevier.com/retrieve/pii/S0006322306015095

46. Frodl T, Szyf M, Carballedo A, Ly V, Dymov S, Vaisheva F, et al. DNA methylation of the serotonin transporter gene (SLC6A4) is associated with brain function involved in processing emotional stimuli. J Psychiatry Neurosci [Internet]. 2015 [cited 2018 Feb 14];40(5):296-305. Available from: http://www.ncbi.nlm.nih.gov/pubmed/25825812.

47. Olsson CA, Foley DL, Parkinson-Bates M, Byrnes G, McKenzie M, Patton GC, et al. Prospects for epigenetic research within cohort studies of psychological disorder: A pilot investigation of a peripheral cell marker of epigenetic risk for depression. Biol Psychol [Internet]. 20101 [cited 2018 Aug 22];83(2):159-65. Available from: https://www.sciencedirect.com/ science/article/pii/S0301051109002543

48. Alexander N, Wankerl M, Hennig J, Miller R, Zänkert S, Steudte-Schmiedgen $\mathrm{S}$, et al. DNA methylation profiles within the serotonin transporter gene moderate the association of 5-HTTLPR and cortisol stress reactivity. Transl Psychiatry [Internet]. 2014 [cited 2017 Oct 18];4. Available from: https:// www.ncbi.n/m.nih.gov/pmc/articles/PMC4203016/pdf/tp201488a.pdf

49. lurescia S, Seripa D, Rinaldi M. Looking Beyond the 5-HTTLPR Polymorphism: Genetic and Epigenetic Layers of Regulation Affecting the Serotonin Transporter Gene Expression. Mol Neurobiol [Internet]. 20178 [cited 2019 Feb 14];54(10):8386-403. Available from: http///inkspringer.com/https:/doi.org/10.1007/s12035-016-0304-6

50. Uddin M, Sipahi L, Li J, Koenen KC. Sex differences in DNA methylation may contribute to risk of PTSD and depression: A review of existing evidence. Depress Anxiety [Internet]. 20131 [cited 2020 Jul 8];30(12):1151-60. Available from: http://doi.wiley.com/https://doi.org/10.1002/da.22167

51. Palma-Gudiel H, Peralta V, Deuschle M, Navarro V, Fañanás L. Epigeneticsby-sex interaction for somatization conferred by methylation at the promoter region of SLC6A4 gene. Prog Neuro-Psychopharmacology Biol Psychiatry. 2019;89:125-31. https://doi.org/10.1016/j.pnpbp.2018.09.002.

52. Żmudzka E, Sałaciak K, Sapa J, Pytka K Serotonin receptors in depression and anxiety: Insights from animal studies. Vol. 210, Life Sciences. Elsevier Inc; 2018. p. 106-24.

53. Sanwald S, Gahr M, Widenhorn-Müller K, Schönfeldt-Lecuona C, Richter K, Connemann BJ, et al. Relation of promoter methylation of the oxytocin gene to stressful life events and depression severity. J Mol Neurosci [Internet]. 201925 [cited 2019 Dec 2];1-11. Available from: http://link. springer.com/https://doi.org/10.1007/s12031-019-01446-1

54. Sanwald S, Widenhorn-Müller K, Montag C, Kiefer M. Relation of promoter methylation of the structural oxytocin gene to critical life events in Major Depression: A case control study. J Affect Disord [Internet]. 20201 [cited 2020 Jul 29];276:829-38. Available from: https://linkinghub.elsevier.com/ retrieve/pii/S0165032720325131

55. American Psychiatric Association. Diagnostisches und statistisches Manual psychischer Störungen : Textrevision. 4th ed. Hogrefe: Sass H, Wittchen HU, Zaudig M, Houben I, editors. Göttingen; 2003.

56. Montgomery SA, Asberg M. A new depression scale designed to be sensitive to change. Br J Psychiatry [Internet]. 19791 [cited 2018 Mar 29]; 134(4):382-9. Available from: http://bjp.rcpsych.org/cgi/doi/https://doi.org/1 $0.1192 /$ bjp.134.4.382

57. Hayasaka Y, Purgato M, Magni LR, Ogawa Y, Takeshima N, Cipriani A, et al. Dose equivalents of antidepressants: Evidence-based recommendations from randomized controlled trials. J Affect Disord [Internet]. 201515 [cited 2018 Apr 26];180:179-84. Available from: https://www.sciencedirect.com/ science/article/pii/S0165032715001512?via\%3Dihub

58. Benkert O, Hippius H. Kompendium der psychiatrischen Pharmakotherapie. 2012 [cited 2018 Apr 26]; Available from: https://books.google.de/books?hl= de\& $|r=\& i d=e 34 f 8| p G T 0 \mid C \& o i=f n d \& p g=P R 5 \& d q=$ benkert + hippius + kompendium\&ots=a4kTW-bnhG\&sig=FIParmjsU8xdHKqAwAsdvh3t05s

59. Schneider F, Niebling W. Psychische Erkrankungen in der Hausarztpraxis. 2008 [cited 2018 Apr 26]; Available from: https://books.google.de/books?hl= de\& $r=\& i d=n T s n B A A A Q B A J \& o i=f n d \& p g=P A 3 \& d q=s c h n e i d e r+$ frand + niebling\&ots $=2 \times 9 \mathrm{m0dNX} 4 Z \&$ sig $=9$ QzKKjRqZcAf-cBf3knbYWvtZAU

60. Woods SW. Chlorpromazine Equivalent Doses for the Newer Atypical Antipsychotics. J Clin Psychiatry [Internet]. 200315 [cited 2018 Apr 26];64(6): 663-7. Available from: http://article.psychiatrist.com/?ContentType=STA RT\&ID $=10000203$

61. Plieger T, Melchers M, Montag C, Meermann R, Reuter M. Life stress as potential risk factor for depression and burnout. Burn Res [Internet]. 20151 [cited 2018 May 29];2(1):19-24. Available from: https://www.sciencedirect. com/science/article/pii/\$2213058614200088

62. Reuter M, Panksepp J, Davis K, Montag C. Affective neuroscience personality scales (ANPS). Göttingen: Hogrefe; 2017

63. Beck A, Steer R, Brown G. Beck-Depressions-Inventar-Revision (BDI-II). Deutsche Version. Hautzinger M, Keller F, Kühner C, editors. Frankfurt/Main: Harcourt Test Services; 2006.

64. Lachmann B, Doebler A, Sindermann C, Sariyska R, Cooper A, Haas H, et al. The Molecular Genetics of Life Satisfaction: Extending Findings from a Recent Genome-Wide Association Study and Examining the Role of the Serotonin Transporter. J Happiness Stud [Internet]. 2020 [cited 2021 Feb 15]; 22(1):305-22. Available from: https://doi.org/https://doi.org/10.1007/s10902020-00231-x, The Molecular Genetics of Life Satisfaction: Extending Findings from a Recent Genome-Wide Association Study and Examining the Role of the Serotonin Transporter.

65. Hu XZ, Lipsky RH, Zhu G, Akhtar LA, Taubman J, Greenberg BD, et al. Serotonin transporter promoter gain-of-function genotypes are linked to obsessive-compulsive disorder. Am J Hum Genet. 2006;78(5):815-26. https:// doi.org/10.1086/503850.

66. Suchiman HED, Slieker RC, Kremer D, Slagboom PE, Heijmans BT, Tobi EW Design, measurement and processing of region-specific DNA methylation assays: the mass spectrometry-based method EpiTYPER. Front Genet [Internet]. 2015 [cited 2018 may 3];6:287. Available from: http://www.ncbi. nlm.nih.gov/pubmed/26442105.

67. Urdan TC. Statistics in plain English. 4th ed. New York: Routledge; 2016.

68. R Development Core Team. R: A Language and Environment for Statistical Computing [Internet]. Vienna, Austria; 2008 [cited 2018 Apr 3]. Available from: http://www.gnu.org/copyleft/gpl.html.

69. Revelle W. Psych: procedures for personality and psychological research [Internet]. Evanston: Northwestern University; 2018 [cited 2019 Sep 10]. Available from: https://scholar.google.de/scholar?hl=de\&as_sdt=0\%2C5\&q= Revelle\%2C+W.+\%282018\%29+psych\%3A+Procedures+for+Personality+a nd+Psychological+Research\%2C+Northwestern+University\%2C+Evanston\%2 $\mathrm{C}+$ Illinois\%2C+USA\%2C\&btnG=

70. Wickham H. ggplot2: elegant graphics for data analysis [Internet]. SpringerVerlag. New-York; 2016 [cited 2019 Sep 10]. Available from: https://books. google.de/books?hl=de\&lr=\&id=XgFkDAAAQBAJ\&oi=fnd\&pg=PR8\&dq=H.+ 
Wickham.+ggplot2:+Elegant+Graphics+for+Data+Analysis.+Springer-Verlag+ New+York,+2016.+\&ots=s0276N9Z7W\&sig=mn0w30ynbjnBrdtpCOpKGnlzkxE

71. Benjamini Y, Hochberg Y. Controlling the False Discovery Rate: A Practical and Powerful Approach to Multiple Testing [Internet]. Vol. 57, Journal of the Royal Statistical Society. Series B (Methodological). WileyRoyal Statistical Society; 1995 [cited 2017 Nov 27]. p. 289-300. Available from: http://www. jstor.org/stable/2346101

72. Carter JS, Garber J. Predictors of the first onset of a major depressive episode and changes in depressive symptoms across adolescence: stress and negative cognitions. J Abnorm Psychol. 2011;120(4):779-96. https://doi. org/10.1037/a0025441.

73. Kendler KS, Kessler RC, Walters EE, MacLean C, Neale MC, Heath AC, et al. Stressful life events, genetic liability, and onset of an episode of major depression in women. Am J Psychiatry [Internet]. 1995 [cited 2018 mar 28]; 152(6):833-42. Available from: http://www.ncbi.nlm.nih.gov/pubmed/ 7755111.

74. Hammen C, Kim EY, Eberhart NK, Brennan PA. Chronic and acute stress and the prediction of major depression in women. Depress Anxiety. 2009;26(8): 718-23. https://doi.org/10.1002/da.20571.

75. Muscatell KA, Slavich GM, Monroe SM, Gotlib IH. Stressful life events, chronic difficulties, and the symptoms of clinical depression. J Nerv Ment Dis. 2009; 197(3):154-60. https://doi.org/10.1097/NMD.0b013e318199f77b.

76. Gibb BE, Butler AC, Beck JS. Childhood abuse, depression, and anxiety in adult psychiatric outpatients. Depress Anxiety [Internet]. 20031 [cited 2020 Jun 17];17(4):226-8. Available from: http://doi.wiley.com/https://doi.org/10.1 002/da.10111

77. Harkness KL, Bruce AE, Lumley MN. The role of childhood abuse and neglect in the sensitization to stressful life events in adolescent depression. J Abnorm Psychol. 2006;115(4):730-41. https://doi.org/10.1037/0021-843X.11 5.4.730.

78. Tram JM, Cole DA. Self-perceived competence and the relation between life events and depressive symptoms in adolescence: mediator or moderator? J Abnorm Psychol. 2000;109(4):753-60. https://doi.org/10.1037/0021-843X.1 09.4.753.

79. Fiske A, Gatz M, Pedersen NL. Depressive symptoms and aging: the effects of illness and non-health-related events [Internet]. 2003. Available from: https://a cademic.oup.com/psychsocgerontology/article-abstract/58/6/P320/597429

80. Romeo RD, McEwen BS. Stress and the adolescent brain. In: Annals of the New York Academy of Sciences. Blackwell Publishing Inc.; 2006. p. 202-14.

81. Lemoult J, Humphreys KL, Tracy A, Ma J-A, Hoffmeister E, Ip IH, et al. Metaanalysis: Exposure to Early Life Stress and Risk for Depression in Childhood and Adolescence [Internet]. Vol. 59, Journal of the American Academy of Child \& Adolescent Psychiatry. 2020 [cited 2021 Jan 18]. Available from: www.jaacap.org

82. Daskalakis NP, Bagot RC, Parker KJ, Vinkers CH, de Kloet ER. The three-hit concept of vulnerability and resilience: toward understanding adaptation to early-life adversity outcome. Psychoneuroendocrinology. 2013;38(9):1858-73. https://doi.org/10.1016/j.psyneuen.2013.06.008.

83. Inoue Y, Stickley A, Yazawa A, Aida J, Koyanagi A, Kondo N. Childhood adversities, late-life stressors and the onset of depressive symptoms in community-dwelling older adults. Aging Ment Heal [Internet]. 2021 [cited 2021 Feb 9]; Available from: https://www.tandfonline.com/doi/abs/https:// doi.org/10.1080/13607863.2021.1875190

84. Lewinsohn PM. A behavioral approach to depression. In: Katz MM, editor. Friedman RJ. The psychology of depression: Contemporary theory and research. John Wiley \& Sons, Inc.; 1974.

85. Dimidjian S, Barrera M, Martell C, Muñoz RF, Lewinsohn PM. The origins and current status of behavioral activation treatments for depression. Annu Rev Clin Psychol [Internet]. 201127 [cited 2021 Feb 8];7:1-38. Available from: www.annualreviews.org

86. Negt P, Brakemeier E, Michalak J, Winter L, Bleich S, Kahl KG. The treatment of chronic depression with cognitive behavioral analysis system of psychotherapy: a systematic review and meta-analysis of randomizedcontrolled clinical trials. Brain Behav [Internet]. 20163 [cited 2021 Feb 8]; 6(8):e00486. Available from: https://onlinelibrary.wiley.com/doi/https://doi. org/10.1002/brb3.486

87. Driessen E, Van HL, Don FJ, Peen J, Kool S, Westra D, et al. The efficacy of cognitive-behavioral therapy and psychodynamic therapy in the outpatient treatment of major depression: A randomized clinical trial. Am J Psychiatry [Internet]. 20131 [cited 2021 Feb 8];170(9):1041-50. Available from: http:// www.bristol.ac.uk/cmm/software/
88. Breslau J, Gilman SE, Stein BD, Ruder T, Gmelin T, Miller E. Sex differences in recent first-onset depression in an epidemiological sample of adolescents. Transl Psychiatry. 2017;7(5):e1139. https://doi.org/10.1038/tp.2017.105.

89. Martin LA, Neighbors HW, Griffith DM. The experience of symptoms of depression in men vs women: Analysis of the national comorbidity survey replication. JAMA Psychiatry [Internet]. 20131 [cited 2020 Sep 29];70(10): 1100-6. Available from: https://jamanetwork.com/

90. Schmitt DP, Realo A, Voracek M, Allik J. Why Can't a man be more like a woman? Sex differences in big five personality traits across 55 cultures. Pers Soc Psychol. 2008;94(1):168-82. https://doi.org/10.1037/0022-3514.94.1.1 68.

91. Murray L, Arteche A, Fearon P, Halligan S, Goodyer I, Cooper P. Maternal postnatal depression and the development of depression in offspring up to 16 years of age. J Am Acad Child Adolesc Psychiatry. 2011;50(5):460-70. https://doi.org/10.1016/j.jaac.2011.02.001.

92. Hawton K, Casañas I Comabella C, Haw C, Saunders K. Risk factors for suicide in individuals with depression: A systematic review. Vol. 147, Journal of Affective Disorders. Elsevier; 2013. p. 17-28.

93. Yehuda R, Daskalakis NP, Lehrner A, Desarnaud F, Bader HN, Makotkine I, et al. Influences of maternal and paternal PTSD on epigenetic regulation of the glucocorticoid receptor gene in Holocaust survivor offspring. Am J Psychiatry [Internet]. 20141 [cited 2021 Feb 8];171(8):872-80. Available from: https://ajp.psychiatryonline.org/doi/abs/https://doi.org/10.1176/appi.ajp.2 014.13121571

94. Philibert RA, Sandhu H, Hollenbeck N, Gunter T, Adams W, Madan A. The relationship of 5HTT ( SLC6A4) methylation and genotype on mRNA expression and liability to major depression and alcohol dependence in subjects from the lowa Adoption Studies. Am J Med Genet Part B Neuropsychiatr Genet [Internet]. 20085 [cited 2018 Feb 14];147B(5):543-9. Available from: http://doi.wiley.com/https://doi.org/10.1002/ajmg.b.30657

95. Sachar EJ, Hellman L, Roffwarg HP, Halpern FS, Fukushima DK, Gallagher TF. Disrupted 24-hour Patterns of Cortisol Secretion in Psychotic Depression. Arch Gen Psychiatry [Internet]. 19731 [cited 2021 Feb 9];28(1):19-24. Available from: https:/jamanetwork.com/journals/jamapsychiatry/fullarticle/4 90813

96. Samuels BA, Hen R. Neurogenesis and affective disorders. Eur J Neurosci [Internet]. 20111 [cited 2020 Oct 9];33(6):1152-9. Available from: https:// onlinelibrary.wiley.com/doi/full/https://doi.org/10.1111/j.1460-9568.2011. 07614.x

97. Gulbins A, Schumacher F, Becker KA, Wilker B, Soddemann M, Boldrin F, et al. Antidepressants act by inducing autophagy controlled by sphingomyelin-ceramide. Mol Psychiatry [Internet]. 20181 [cited 2020 Jul 21];23(12):2324-46. Available from: https://pubmed.ncbi.nlm.nih.gov/3003 $8230 /$

98. Moncrieff J. What does the latest meta-Analysis really tell us about antidepressants? Epidemiol Psychiatr Sci [Internet]. 2018 [cited 2021 Feb 9]; 27(5):430-2. Available from: https://doi.org/https://doi.org/10.1017/S204 5796018000240, What does the latest meta-analysis really tell us about antidepressants?.

99. Warren J. Network meta-analysis of antidepressants [Internet]. Vol. 392, The Lancet. Lancet Publishing Group; 2018 [cited 2021 Feb 9]. p. 1010-1. Available from: http://handbook-5-1.cochrane.org/

100. Munkholm K, Paludan-Müller AS, Boesen K. Considering the methodological limitations in the evidence base of antidepressants for depression: A reanalysis of a network meta-analysis. BMJ Open [Internet]. 20191 [cited 2021 Feb 9];9(6):24886. Available from: http://bmjopen.bmj.com/

101. Cipriani A, Furukawa TA, Salanti G, Geddes JR, Higgins JP, Churchill R, et al. Comparative efficacy and acceptability of 12 new-generation antidepressants: a multiple-treatments meta-analysis. Lancet. 2009;373(9665): 746-58. https://doi.org/10.1016/50140-6736(09)60046-5.

102. Cohen J. Statistical power analysis for the behavioral sciences. 2nd ed. Hillsdale: Erlbaum; 1988

\section{Publisher's Note}

Springer Nature remains neutral with regard to jurisdictional claims in published maps and institutional affiliations. 